\title{
KAJIAN ESTETIKA, FUNGSI, DAN MAKNA UANG KERTAS SERI TEUKU UMAR DAN CUT NYAK DIN
}

\author{
Anissa Mei Primasanthi ${ }^{1}$, Nooryan Bahari ${ }^{2}$, Sarah Rum Handayani ${ }^{3}$ \\ ${ }^{1}$ Mahasiswa Pascasarjana UNIVERSITAS SEBELAS MARET, ${ }^{2,3}$ Dosen Pascasarjana UNIVERSITAS \\ SEBELAS MARET \\ 1anissameip@uns.ac.id
}

\begin{abstract}
Money as a medium communication between ruler with his subjects so that all symbol reflect social conditions and culture. Aesthetic design currency series Teuku Umar and Cut Nyak Din represent symbols culture local knowledge of social values cultural and religious made money have a high art.
\end{abstract}

Keywords: Aesthetic, semiotic Pierce, semiotic Barthes, paper money Indonesian.

Relevance to Visual Communication Design Practice: Paper money design series Teuku umar and Cut Nyak Din is one of the visual communicationdesignin the form of the print paper.

\section{PENDAHULUAN}

Visual uang kertas Indonesia periode Sukarno dan Suharto terdiri dari bermacam-macam seperti seperti seri flora dan fauna, seri binatang, seri perajin, pekerja, budaya, dan seri pahlawan. Banyak ragam visual uang menunjukkan sifat dinamis masyarakat yang senantiasa termotivasi menciptakan kreativitas dan inovasi baru dalam menjawab tantangan lingkungan, budaya, ekonomi, dan politik sesuai zamannya (Kartiwa, 2009: 5). Desain uang kertas tidak lepas dari fenomena kebudayaan yang meliputi teknologi, religi, nilai-nilai spiritual, sistem ekonomi dan sosial. Setelah tahun 1998, BI (Bank Indonesia) mulai konsisten membuat mata uang dengan tema pahlawan Nasional sebagai ilustrasi dalam mata uang kertas Indonesia di masa depan. Gambar tokoh-tokoh pahlawan nasional yang ditampilkan dalam uang rupiah sebagai media kesadaran sejarah untuk mempertahankan identitas kebangsaan ditengah mulai mengglobalnya budaya Barat agar bangsa Indonesia tertanam dalam dirinya semangat nasionalisme, patriotisme, demokrasi, dan cinta tanah air (Subaryono, 2013: 4). Namun, dalam kenyataannya beberapa kasus dimana beberapa WNI (Warga Negara Indonesia) tidak menghargai jasa para pahlawan terlihat dari fenomena-fenomena yang terjadi belakangan ini.

Penelitian ini, difokuskan pada desain mata uang seri pahlawan Teuku Umar dan Cut Nyak Din yang gigih dan tabah mempertahankan tanah air, bangsa, dan agama dalam mengahadapi kolonialisme. Teuku Umar dan Cut Nyak Din merupakan seri pahlawan yang terbit tahun 1985 dan 1998 periode Suharto, pemilihan dua tokoh ini didasarkan karena kedua sosok ini menggambarkan pasangan pahlawan pada perang Aceh, dimana masih banyak sisi misteri dibalik sosok kedua tokoh ini. Kedua pahlawan ini adalah sepasang suami istri yang berjuang pada perang aceh. Aceh memiliki tradisi kuat yang diwariskan nenek-moyang mereka. Visual lembar rupiah merefleksikan banyak nilai-nilai history, sosial budaya, identitas nasional, ideologi, dan pesan politik. 


\section{TEORI DAN METODE}

\section{Estetika}

Estetika berasal dari bahasa Yunani "aisthetika" artinya hal-hal yang bisa diserap pancaindera. Oleh karena itu, estetika sering disebut sebagai persepsi indera (sense of perception). Alexander Baumgerten (17141762), seorang filsuf Jerman yang memperkenalkan kata "aisthetika". Keindahan (beauty) adalah pengertian seni yang telah diwariskan bangsa Yunani dari Plato yang mengartikan keindahan sebagai karakter yang indah dan hukum yang indah (Kartika, 2004: 9). Sedangkan, Aristoteles merumuskan keindahan sebagai sesuatu yang baik dan menyenangkan. Sebaliknya, Plotinus mengungkapkan keindahan sebagai ilmu dan kebajikan yang indah. Bangsa Yunani mengenai kata keindahan dalam estetis disebut "symmetria" untuk keindahan visual sedangkan, harmoni untuk keindahan pendengaran.

\section{Semiotika}

Semiotika mengalami perkembangan yang pesat yang awalnya sebagai ilmu tentang tanda saja, kemudian mulai mengkaji bagaimana tanda-tanda itu berfungsi, hubungannya dengan tanda-tanda lain, dan proses pengiriman dan penerimaan oleh penggunanya (Sobur, 2013: 19). Analisis mengenai fungsi tanda dikenal dengan sintaksis, analisis yang berhubungan dengan tanda-tanda dikenal sebagai semantik sedangkan, analisis tanda yang berkaitan dengan pengirimannya adalah pragmatik.

\section{a. Teori Semiotika Pierce}

Pierce memaknai tanda sebagai ilmu tentang tanda dan segala yang berhubungan dengan tanda. Menurut Sumbo Tinarbuko dalam bukunya Semiotika Komunikasi Visual menjelaskan tanda dalam hubungan dengan acuannya dibedakan menjadi tanda yang dikenal dengan ikon, indek, dan symbol kemudian dihubungkan dengan ground, objek, dan interpretant. Semiotika Pierce memandang tanda bukan sebagai struktur tetaoi proses pemahaman (signifikasi komunikasi). Teori Pierce dapat diterapkan pada tanda yang berupa gambar untuk melihat makna dibalik uang kertas seri pahlawan Teuku Umar dan Cut Nyak Din.

\section{b. Teori Roland Barthes}

Lima kode ditinjau Barthes adalah kode hermeneutic (kode teka-teki), kode semik (makna konotatif), kode simbolik, kode proapretik (logika tindakan), dan kode gnomic atau kode kultural. Analisis ini untuk membangun sistem klasifikasi unsur-unsur narasi merujuk pada peristiwa itu lebih masuk akal, rincian yang paling meyakinkan. Teori penting yang ditemukan Bartes adalah peran pembaca (the reader), berupa denotasi adalah sistem signifikasi tingkat pertama dan konotasi merupakan tingkat kedua. Konotasi identik dengan ideologi berfungsi mengungkapkan dan membenarkan nilai-nilai dominan yang berlaku dalam periode tertentu (Sobur, 2013:71). Barthes beranggapan ideologi dan mitos saling terkait dimana ideologi sebagai kesadaran palsu yang membuat orang hidup di dunia yang imajiner dan ideal, meskipun secara realitanya tidak demikian. 


\section{Metode}

Penelitian ini merupakan penelitian bidang ilmu kajian seni dengan menggunakan penelitian kualitatif pendekatan kritik seni. Kritik seni sebagai usaha pemahaman kualitas karya seni dengan dilakukan analisis yang logis dan argumentatif untuk menafsirkan karya seni, dan menumbuhkan apresiasi serta tanggapan terhadap seni sampai aktivitas evaluasi nilai baik dan buruk (Bangun, 2000: 2). Tujuan kritik seni untuk penikmat karya seni memperoleh informasi dan pemahaman yang berkaitan dengan kualitas suatu karya sehingga menumbuhkan apresiasi serta tanggapan terhadap karya seni (Feldman, 1967: 448). Secara umum penelitian yang menggunakan analisis kualitatif didefinisikan sebagai penelitian yang menghasilkan data deskriptif berupa kata-kata atau tindakantindakan yang dapat diamati dengan menekankan pada pengembangan konsep dan pemahaman pola yang ada pada data.

\section{HASIL DAN PEMBAHASAN}

Uang Kertas seri Pahlawan Teuku Umar emisi 1986 nominal 5000.

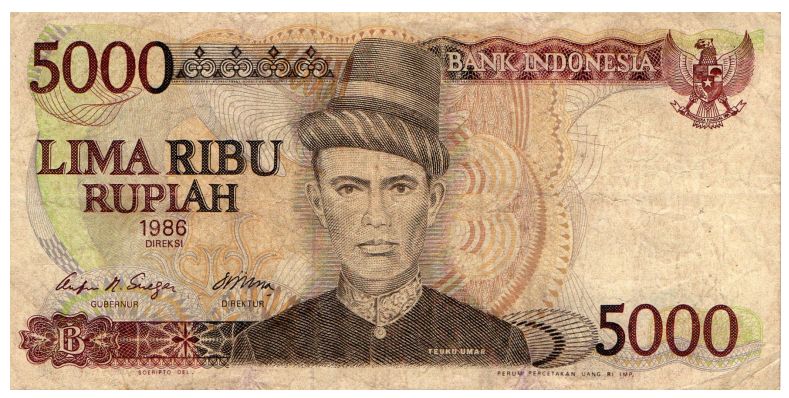

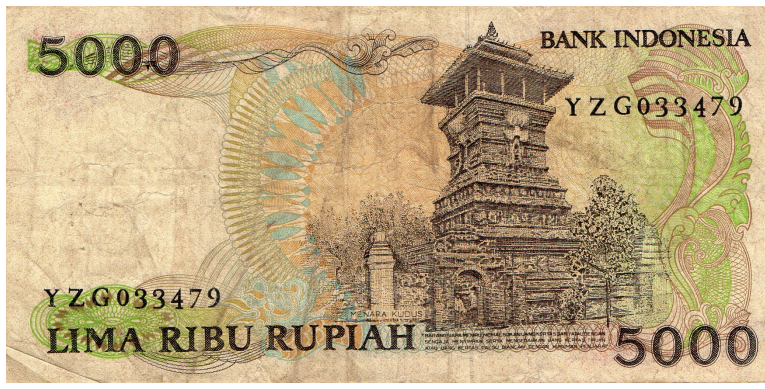

Gambar 1 Uang kertas nominal 5000 Sumber: Dokumen Pribadi Penulis

\section{Qualisign, Sinsign, dan Legisign}

\section{1). Qualisign}

Uang seri Teuku Umar nominal 5000, terbit tanggal 9 Desember 1986 dominasi warna coklat memberi kesan netral, kuno, klasik, dan berukuran 15,2 x 7,6 cm. Terdiri dari nominal angka 5000 disisi kanan atas, kiri bawah tipe huruf sans serif berukuran sama. Tulisan BANK INDONESIA ukuran kecil blok putih agar terlihat kontras dengan background belakang ornamen fantasi pada sisi kiri atas dan huruf SERIBU RUPIAH kiri tengah memakai tipe huruf serif ukuran lebih besar memberi kesan klasik dan anggun. Garis-garis Guilloche memenuhi background lembar kiri dengan garis yang melengkung tipis mengesankan keindahan, lemas, lincah, dan meliuk berbentuk roset dengan garis-garis yang tersusun rapi dan indah. Gradasi rosette bentuk berbeda yang bertumpukan mengesankan ruang yang harmonis. Garis lengkung yang bergerak dengan arah berbeda membentuK transisi melahirkan gerakan susunan yang harmonis.

\section{2). Sinsign}

Gambar Utama uang nominal 5000 tahun 1986 ialah Teuku Umar sosok pahlawan yang ahli dalam strategi, dengan strategi terkenal "dua wajah" mampu mengelabuhi Belanda. 
Teuku umar posisi menghadap depan, dengan pandangan mata tajam memperlihatkan sikap keras Teuku Umar dalam melawan musuh. Busana yang dipakai Teuku Umar merupakan busana adat Aceh berupa kupiah meukeutop yang menghiasi kepala dan baju meukeuh sebagai identitas sosok tokoh. Tulisan "LIMA RIBU RUPIAH” tipe serif pada lembar depan dibuat lebih besar dan beroutline untuk menekankan/emphasis.

Menara kudus menghiasi lembar belakang uang kertas ini merupakan sebuah masjid yang menaranya berbentuk candi memiliki muatan pesan bahwa penyebarkan agama islam (islamisasi) di pulau Jawa malalui pendekatan budaya Hindu. Lembar belakang dihiasi garis-garis tipis yang membentuk ornamen abstrak kepala Garuda dan Ornamen floral pada lembar belakang berupa garis-garis tipis.

\section{3). Legisign}

Pemilihan Ilustrasi Teuku Umar berdasarkan Kappres No.087/TK/19736 November 1973 yang menetapkan Dr. Sutomo sebagai pahlawan nasional. Teknik cetak yang digunakan dalam pembuatan uang adalah teknik intaglio dan teknik offset. Tanda tangan Gubernur BI: Mr. Arifin M. Siregar dan Direktur Mr. Sujitno Siswowidagdo terdapat pada sisi kiri lembar uang sebagai legalitas uang sah beredar di Nusantara. Sedangkan, pemilihan warna pada uang berdasarkan teori warna Teori Mussel dimana Munsell menyelidiki warna dengan standar warna untuk aspek fisik dan psikis (Kusrianto, 2007: 48). Tanda air/watermark M.C. Tiahahu sebagai salah satu unsur pengaman uang.

\section{Ikon, Indeks, dan Simbol}

\section{1). Ikon}

Ilustrasi pada desain uang ini terdiri dari ilustrasi Teuku Umar, pemimpin perang Aceh dan ilustrasi menara Kudus sebagai ikon dari objek foto.

2). Indeks

Ilustrasi Teuku Umar dan tulisan "LIMA RIBU RUPIAH"menggunakan teknik engraving menjadi teksturnya kasar untuk memudahkan tunanetra mengenali uang tersebut.

\section{3). Simbol}

Teuku Umar menjadi simbol kepemimpinan rakyat Aceh pada perang Aceh. Kupiah meukeutop dan baju meukeuh yang dipakai Teuku Umar simbol busana khas Aceh. Burung Garuda berada di pojok kanan atas simbol NKRI. Hiasan fantasi berupa ornament Siak motif bintang berdada wajik simbol dari kearifan dan kerukunan. Menara Kudus simbol penyebaran islam di pulau Jawa.

\section{Analisis Sintaksis, Semantik, dan Pragmatik}

\section{1). Analisis Sintaksis:}

\section{Warna: Coklat}

\section{Layout Desain Depan:}

Teks "LIMA RIBU RUPIAH" bertipe serif berukuran besar serta ber-outline berada di kiri menjadi penekan/emphasis sehingga menjadi point of interest dengan ilustrasi Teuku Umar terlihat memakai topi kebesaran kupiah meukeutop dan baju meukeuh diposisi tengah lembar.

Adanya keseimbangan asimetris pada lembar depan uang kertas ini, seperti ilustrasi 
pahlawan Teuku Umar berada ditengah sedangkan, teks "LIMA RIBU RUPIAH", tahun terbit, nominal dan logo BI diseimbangkan di sebelah kanan watermark M.C Tiahahu, nominal, logo Garuda dan tulisan "BANK INDONESIA".

Unity antara ilustrasi, teks dan warna terlihat mengusung konsep adat Sumatra Jawa dan keislaman dari sosok Teuku Umar pemuda Aceh dengan pakaian khas Aceh dan ragam hias Siak sisi kiri bawah dengan ilustrasi belakang lembar, menara Kudus.

\section{Layout Belakang:}

Ilustrasi masjid Agung sebagai point of interest. Keseimbangan asimetris. Tidak ada unity antara desain depan dan belakang.

\section{Ragam Hias:}

Garis Guilloche, hiasan relief, rosette, hiasan fantasi, dan ragam hias siak dari Sumatera Barat, motif kepala garuda.

\section{2). Analisis Semantik}

\section{Makna Desain Depan:}

Teuku Umar dalam uang kertas ini tergambar mengenakan topi kebesaran kupiah meukeutop dan baju meukeuh khas aceh. Kupiah meukeutop adalah kopiah lonjong ke atas dilengkapi lilitan tangkulok, sebuah lilitan dari tenun sutra. Pakaian yang dikenakan Teuku Umar bernama baju Meukeuh adalah baju yang terbuat dari tenun sutra biasanya bewarna dasar hitam. Pada baju Meukeuh dilengkapi kerah mirip baju China dihiasi sulaman benang emas sebagai simbol laki-laki Aceh.
Teuku Umar sosok pahlawan yang inspiratif memiliki keteguhan untuk melawan penjajahan tidak tergiur akan kedudukan tinggi dan kekayaan yang ditawarkan Belanda dan terkenal dengan sikap keras terhadap penjajah dan terkenal dengan ketajaman akal yang susah dikalahkan Belanda. Siasat Teuku Umar yaitu taktik "Dua Rupa" yang bisa membuat musuh percaya kepadanya dan menjadikannya kaki tangan bahkan mendapat gelar Johan Pahlawan dengan niat untuk merebut persenjataan musuh. Perjuangan Teuku Umar dalam melawan Belanda mengalami banyak sekali rintangan dari caci maki rakyat Aceh sampai tekanan para pejuang Aceh (Priatna, 2013:45).

\section{Makna Desain Belakang:}

Menara kudus tergambar pada lembar belakang uang kertas merupakan sebuah mesjid yang memiliki menara berbentuk candi, bukti akulturasi budaya Hindu-Jawa dengan Islam berlokasi di daerah Kauman, Kudus. Pendiri masjid ini adalah kyai Ja'far Sodig lebih dikenal Sunan Kudus.

Pengaruh arsitektur Hindu terlihat jelas pada Menara dan gerbang-gerbang pintu masuk. Atap dari masjid kudus ini juga bersusun tiga konstruksi kayu layaknya masjid Jawa Kuno. Pengaruh Cina yang paling mencolok terlihat pada hiasan-hisan porselen Cina pada dinding-dinding masjid (Hardinoto, 2007:32). Menara Kudus bukti bahwa Sunan Kudus dalam menyebarkan islam tetap mengangkat budaya Hindu yang sudah sangat melekat pada rakyat Jawa sehingga agama islam bisa diterima rakyat Jawa dengan baik. 


\section{3). Analisis Pragmatik}

\section{Fungsi sebagai :}

- Teuku Umar seorang ahli strategi yang harus diteladani rakyat Indonesia.

- Memperkenalkan bangunan bersejarah kepada rakyat Indonesia serta sebagai promosi wisata.

\section{Analisis Denotasi dan Konotasi}

\section{1). Denotasi}

Teuku Umar adalah pahlawan dari perang Aceh yang terkenal memiliki kecerdasan dalam bertaktik hingga mampu mengelabuhi Balanda. Perjuangan Teuku Umar diiringi dengan caci maki dari pihak rakyat Aceh dan pemuka agama yang menganggap beliau berkianat tetapi beliau tetap setia bahkan mau menyerahkan jiwa dan raga untuk bangsa dan Tanah Airnya. Teuku Umar di dalam ilustrasi uang kertas Indonesia berada di nominal 5000, merupakan nominal terendah zaman itu setelah nominal 1000 .

\section{2). Konotasi}

Teuku Umar merupakan Pahlawan yang berasal dari Aceh terlihat dari identitas pakaian yang dipakainya. Sifatnya yang keras menentang penjajahan patut menjadi contoh bagi generasi Bangsa Indonesia untuk menentang keras kolonialisme. Ditilik dari sejarah Teuku Umar berpaling memihak Belanda dengan maksud untuk memperkuat persenjataan pejuang Aceh bisa menjadi nilai positif dan negatif. Nilai positif Teuku Umar memiliki taktik/strategi agar tidak terjadi banyak korban saat perang sedangkan, nilai nilai negatifnya Teku Umar terlihat tidak mempercayai kekuatan pejuang Aceh dan mengandalkan alat-alat canggih dari pihak musuh. Lembar belakang bergambar Menara Kudus sebagai bukti islamisasi di pulau Jawa dengan proses transisi dari agama Hindu ke Islam.

\section{Uang Kertas seri Pahlawan Cut Nyak Din emisi 1998 nominal 10000.}

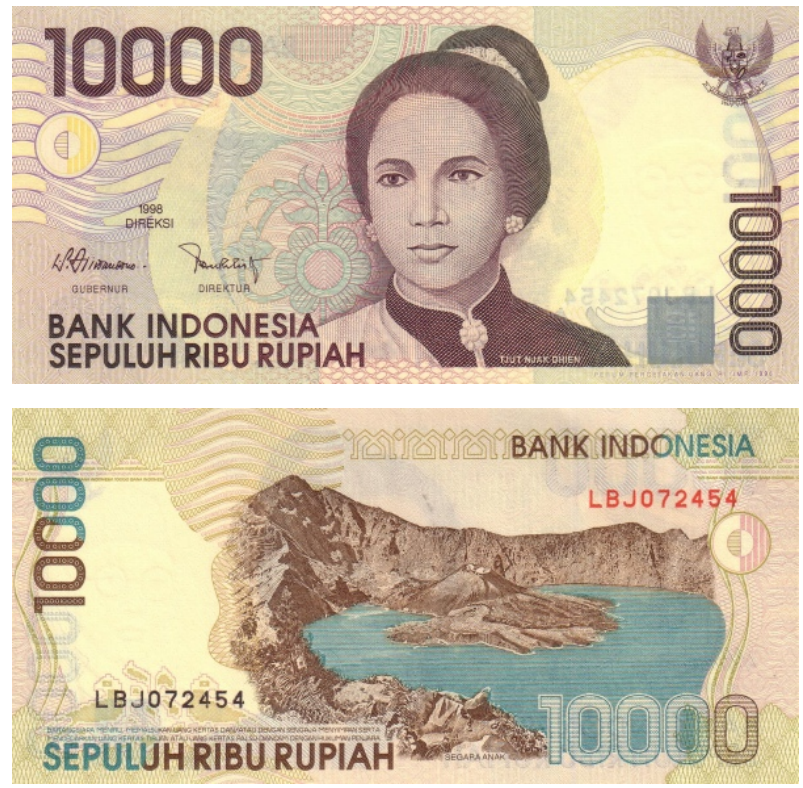

Gambar 2 Uang kertas nominal 10000 Sumber: http://mr-realfact.blogspot.co.id

\section{Qualisign, Sinsign, dan Legisign}

\section{1). Qualisign}

Uang seri Cut Nyak Din nominal 10000, terbit tanggal 19 Februari 1998 dominasi warna coklat memberi kesan kuno, klasik, dan netral berukuran $14,8 \times 7,2 \mathrm{~cm}$. Lembar depan terdiri dari nominal angka 10000 disisi kiri atas dan kanan bawah posisi vertikal tipe huruf sans serif. Tulisan BANK INDONESIA dan SERIBU RUPIAH rata kiri berada di kiri bawah tipe sans serif memberi kesan modern dan kontemporer. 
Hiasan yang memenuhi lembar depan membentuk tektur semu terdiri dari garisgaris yang melengkung / bergelombang, vertikal, dan miring. Garis lengkung melambangkan sesuatu yang indah, lemas, lincah dan garis vertikal menyiratkan kekokohan dan kekuatan. Sedangkan, garis miring menunjukkan gerakan, hidup dan dinamis. Bidang dipenuhi diagonal oval tersusun berirama, jarak sama dan teratur. Garis-garis tipis yang berombak atau garis lengkung majemuk terlihat gerakan indah disebut "line of beauty" berepetisi dengan diisi garis yang bergelombang rapat sehingga tidak menjemukan. Tekstur nyata terdapat pada ilustrasi tokoh dan nominal uang serta tulisan, angka dan gambar pahlawan.

\section{2). Sinsign}

Gambar Utama uang nominal 10000 tahun 1998 ialah Tokoh Cut Nyak Din memakai baju Dara Baro, baju kurung berlengan panjang dengan kerah baju yang menyerupai kerah baju khas Cina, memakai anting-anting serta bros bunga dengan rambut disanggul kecil dengan hiasan bercorak bunga. Lembar depan terdapat background garis-garis geometri lingkaran berisi tulisan mikro teks BANK INDONESIA 10000 berulang-ulang serta ornament yang motif bunga.

Bidang diagonal lingkaran yang berisi setengah lingkaran berada di sisi kiri atas adalah rectoverco gambar ornamen beradu tepat saling mengisi pada bagian depan dan belakang akan terlihat utuh apabila diterawang kearah cahaya dan diagonal persegi bewarna abu-abu sebagai laten image, bertuliskan BI tersembunyi hanya dapat dilihat dari sudut pandang tertentu.
Lembar belakang uang ini terdapat ilustrasi Segara Anak adalah kawah gunung Rinjani tepat di desa Sembalung Lawang, pulau Lombok, Nusa Tenggara Barat mendominasi. Angka 10000 di sisi kanan dengan posisi vertikal dibentuk dengan style iluminasi huruf yaitu menghias badan huruf yang semula kosong menjadi berisi dan lebih indah berupa pengulangan angka 10000 serta bergradasi warna coklat biru.

\section{3). Legisign}

Pemilihan Ilustrasi Cut Nyak Din menurut SK Presiden RI No.106/1964 menetapkan Tjut Njak Dien pahlawan Nasional. Tanda tangan Gubernur BI: Mr.J.Soedradjad Djiwandono dan Direktur Mr. Mukhlis Rasyid terdapat kiri bawah lembar uang sebagai tanda uang sah beredar di wilayah Indonesia. Pemilihan warna pada uang berdasarkan teori warna Teori Mussel dimana Munsell menyelidiki warna dengan standar warna untuk aspek fisik dan psikis (Kusrianto, 2007:48). Tanda air/ watermark gambar pahlawan nasional W.R. Soepratman untuk pelindung uang dari pemalsuan. Bentuk geometri persegi merupakan laten image BI tersembunyi dan dapat dilihat dari sudut tertentu. Aspek pengaman berupa Benang Pengaman akan memendar di bawah sinar $\mathrm{UV}$, rectoverso hanya dapat dilihat dgn kaca pembesar.

\section{Ikon, Indeks, dan Simbol}

\section{1). Ikon}

Lembar depan bergambar Cut Nyak Din dan lembar belakang bergambar pemandangan Ngarai Sianok menjadi ikon dari objek foto. 


\section{2). Indeks}

Ilustrasi Cut Nyak Din, angka, dan teks dibuat dengan cetak intaglio terasa kasar jika diraba. Bentuk diagonal persegi bewarna silver, mengandung tulisan tersembunyi logo BI bisa dilihat dari sudut tertentu.

\section{3). Simbol}

Cut Nyak Din, sosok perempuan bijaksana, tegar, pemberani dan berprinsip kuat memiliki cita-cita membebaskan rakyat Aceh dari belenggu Belanda mewakili kepemimpinan perempuan masa perang Aceh. Burung Garuda adalah simbol NKRI.

\section{Analisi Sintaksis. Semantik, dan Pragmatik}

\section{1). Analisis Sintaksis:}

Warna : coklat

\section{Layout Depan:}

Ilustrasi Cut Nyak Din lengkap dengan pakaian adat aceh yang dipakainya terlihat besar ditengah lembar menjadi point of interest bahkan emphasis daripada elemen lainnya. Sequence/urutan dimana dibuat prioritas pertama yang dibaca sampai yang boleh dibaca terakhir sehingga dalam layout ini sequence membentuk huruf C.

Elemen-elemen layout seperti teks, warna, ilustrasi, ornamen bunga pada latarbelakang lembar depan memberi kesan unity ilustrasi Cut Nyak Din dengan motif bunga pada lembaran yang mengesankan feminism.

\section{Layout Belakang:}

Ilustrasi danau Segara Anak terlihat mendominasi lembar belakang yang posisinya berada di sebelah kanan, dengan teks, rectoverco untuk menyeimbangkan watermark WR. Soepratman dan teks berada di kanan, nominal angka yang buat vertical mengesankan keseimbangan asimetris.

Tidak ada unity antara desain depan dan belakang uang ini, depan yang mengusung konsep feminisme sedangkan lembar belakang memberikan informasi atau promosi wisata alam di daerah Nusa Tenggara Barat.

\section{Ragam Hias:}

Garis-garis vertikal, lengkung, dan miring membentuk hiasan motif bunga.

\section{2). Analisis Semantik}

\section{Makna Desain Depan:}

Cut Nyak Din tergambar memakai baju Dara Baro dengan rambut digulung dengan sanggul berupa lempengan berbentuk rangkaian bunga bersusun dan anting-anting dan bros bermotif bunga sebagai ciri khas pakaian adat perempuan Aceh. Dominasi warna coklat sebagai lambang dapat dipercaya dan bertahan memberi kesan sosok Tjut Nyak Dien adalah wanita Aceh berjiwa ksatria, kuat, pantang menyerah, setia mendampingi Teuku Umar keadaan apapun, serta memegang prinsip melawan penjajahan.

Cut Nyak Din adalah sosok yang mewakili kepemimpinan wanita pada perang Aceh melawan kolonialisme Belanda bersama suami, wanita Aceh rela hidup di medan perang bahkan ikut berperang bersama suami mereka. Memperlihatkan peran wanita aceh tidak hanya pasif dibelakang suami tetapi juga aktif dalam mempertahankan cita-cita kebangsaan dan agama. Saat suami meninggal Cut Nyak Din tetap melanjutkan pertempuran 
bahkan menjadi buronan paling berbahaya bagi Belanda.

Cut Nyak Din simbol kepemimpinan wanita masa perang Aceh. Wanita yang identik dengan kelembutan, sosok yang lemah dan tak berdaya dipatahkan dengan kemunculan inspirator wanita Indonesia yaitu Cut Nyak Din yang berani ikut berperang bersama pasukan Aceh, sifat tangguh, bijaksana, tabah, dan pantang menyerah melawan Belanda bisa menjadi teladan bagi kaumnya.

\section{Makna lembar belakang:}

Mempromosikan atau mengenalkan kekayaan alam Indonesia Segara Anak kepada seluruh bangsa Indonesia dan bangsa Lain.

\section{3). Analisis Pragmatik}

\section{Fungsi sebagai:}

- Tauladan bagi wanita Indonesia agar bisa menjadi wanita pemberani, mampu memimpin, sabar dan tabah menghadapi cobaan dan teguh pendirian seperti Cut Nyak Din.

- Memperkenalkan wisata alam dan kekayaan alam Indonesia yang ada di Lombok.

\section{Analisis Denotasi dan Konotasi}

\section{1). Denotasi}

Uang kertas seri Cut Nyak Din nominal 10000 dengan dominasi warna coklat. Cut Nyak Din tergambar memakai baju Dara Baro sebagai ciri khas perempuan Aceh. Cut Nyak Din adalah wanita pertama yang memimpin pasukan Aceh melawan Marose Belanda yang kejam bersama suaminya Teuku Umar. Saat
Teuku Umar meninggalkanpun Cut Nyak Din tetap melanjutkan pertempuran bahkan menjadi buronan paling berbahaya bagi Belanda. Kesehatan Cut Nyak Din yang menurun drastic dari mata yang mulai rabun, rambut memutih, berbagai penyakit mulai menyerang dirinya, tidak membuat Cut Nyak Din menyerah kepada Belanda. Kaki tangan Cut Nyak Din bernama Pang Lot merasa iba dan menyerahkan diri kepada Belanda sehingga Cut Nyak Din diasingkan ke Priangan bahkan saat diasingkanpun tidak mau mendapat bantuan dari Belanda dan menjadi guru agama di tempat pengasingan tersebut. Ilustrasi Cut Nyak Din berada di nominal 10000, nominal paling besar kedua setelah 20000 seri Ki Hadjar Dewantara.

\section{2). Konotasi}

Cut Nyak Din simbol kepemimpinan perempuan masa perang Aceh. Wanita yang identik dengan kelembutan, sosok yang lemah dan tak berdaya dipatahkan dengan kemunculan inpirator bagi perempuan Indonesia yaitu Cut Nyak Din menjadi teladan bagi kaumnya. Keberadaan sosok Cut Nyak Din pada uang kertas Indonesia nominal 10000 lebih besar daripada nominal 5000 seri Teuku Umar, jika dilihat dari sejarah, Teuku Umar adalah suami dari Cut Nyak Din, sedangkan dalam ajaran islam sosok laki-laki diposisikan sebagai imam bagi perempuan namun, keberadaan dinominal lebih rendah daripada Cut Nyak Din memberi banyak penafsiran tersendiri. Cut Nyak Din berjuang dibelakang Teuku Umar dengan memberikan masukan-masukan pemikiran serta nasehat bahkan segala keputusan yang diambil Teuku Umar terkadang terpengaruh dari pemikiranpemikiran Cut Nyak Din. Saat Teuku Umar 
beralih ke pihak Belanda, Cut Nyak Din-lah yang menyadarkan Teuku Umar untuk kembali dan percaya kepada kemampuan pasukan Aceh.

\section{KESIMPULAN}

1. Teuku Umar dan Cut Nyak Din merupakan dua pasang tokoh Aceh dengan semangat juang yang tinggi rela mati demi tanah air maka perlu diteladani bagi Bangsa Indonesia akan semangat dan kecintaan mereka kepada tanah Air.

2. Masyarakat Aceh adalah masyarakat islam dimana nilai-nilai sosial budaya dan segisegi kehidupan bersumber pada Al-Quran dan hadis sehingga jika kelangsungan hidup agama islam dan tanah air terancam, mereka akan menghadapi dengan kesatuan yang tinggi dan hanya mengenal syahid atau menang.

3. Penempatan Teuku Umar dinominal 5000 dan Cut Nyak Din dinominal 10000 yang ditilik dari sejarah menyebabkan berbagai persepsi yang berbeda-beda. Masa perjuangan Teuku Umar yang tidak lepas dari pengaruh Cut Nyak Din, bahkan saat Teuku Umar wafat, Cut Nyak Din tetap meneruskan perjuangan. Pengaruh Cut Nyak Din baik secara pasif atau aktif pada perang Aceh terlihat lebih mendominasi dibandingkan Teuku Umar.

4. Ikon-ikon budaya yang ditampilkan dalam mata uang ini menunjukkan identitas nasional baik dari busana adat khas Aceh, motif yang diangkat, logogram burung garuda, bangunan sejarah dan kekayaan alam Indonesia.

5. Uang seri Teuku Umar terbit tahun 1986 dengan seri Cut Nyak Din terbit tahun
1998 mengalami perkembangan dari segi pengaman uang makin diperbanyak.

6. Pendekatan semotik Pierce dan semiotik Barthes pada desain uang kertas berupa telaah bahasa rupa dalam perspektif Desain Komunikasi Visual dan dimensi kultural historis. Penelitian ini akan menemukan kelebihan dan kelemahan penerapan semiotika Pierce dengan Bartes. Semiotika Pierce unggul dalam merombak tandatanda visual yang terdapat di dalam sebuah desain sedangkan kelemahannya tidak menjelaskan fungsi dibalik tanda-tanda tersebut dalam lingkungan sosial budayanya. Sedangkan, semiotika Barthes memiliki kelebihan dalam mengungkapkan tanda-tanda dilihat dari ruang lingkup lingkungan sosial budaya tetapi lemah dalam merombak tanda-tanda visual desain karena hanya menganalogikan tanda visual kedalam bahasa.

\section{REFERENSI}

[1] Anggraini S, Lia dan Kirana Nathalio. 2013. Desain Komunikasi Visual (DasarDasar Panduan untuk Pemuls). Bandung: Nuansa Cendekia.

[2] Bahari, Nooryan. 2014. Kritik Seni. Yogyakarta: Pustaka Pelajar.

[3] Bangun, Sem C. 2000. Kritik Seni Rupa. Bandung: ITB

[4] Bungin, M.Burhan. 2008. Penelitian kualitatif. Jakarta: Kencana Prenada Media Group.

[5] Budiman, Kris, 2011. Semiotika Visual (Konsep, Isu, dan Problem Ikonisitas). Yogyakarta: Jalasutra.

[6] Fitriani, Rahmawati, 2008. Perjalanan Panjang ORI (Oeang Republik Indonesia). Bandung: PT. Remaja Rosdakarya. 
[7] Husodo, Siswono Yudo. 2010. Mencari Indonesia 2 (Batas-batas Rekayasa Sosial. Jakarta : LIPI Press.

[8] Ibrahim, Muchtaruddin. 1996. Cut Nyak Din. Jakarta: CV. Defit Prima Karya.

[9] Kartika, Darsini Sony dan Perwira, Nanang Ganda. 2004. Pengantar Estetika. Bandung: Rekayasa Sains.

[10] Kartiwi, Suwati, 2009. Mata Uang Indonesia dan Perjuangan Pemuda. Jakarta: Kementerian Negara Pemuda dan Olahraga Republik Indonesia.

[11] Kusrianto, Adi. 2007. Pengantar Desain komunikasi Visual. Yogyakarta: ANDI OFFSET.

[12] Krisnadi,T. 2006. Sejarah Uang. Bandung: PT. Remaja Rosdakarya.

[13] Maharsi, Indiria. 2013. Tipografi. Jakarta: PT.Buku Seru.

[14] Priatna, Angga. 2013. Nama dan Kisah Pahlawan Indonesia. Jakarta Selatan: PT. Trans Media

[15] Tambunan, Tulus TH. 2001. Sedang Berkembang Industrialisasi di Negara. Jakarta: Ghalia Indonesia

[16] Suhartono. 2010. Sejarah Pergerakan Nasional. Yogyakarta: Media Perkasa.

[17] Sudirman, Adi. 2014. Sejarah Lengkap Indonesia. Yogyakarta: DIVA Press.

[18] Sunaryo, Aryo. 2011. Ornamen Nusantara. Semarang: Effhar Offset.

[19] Sumardjo, Jakop. 2000. Filsafat Seni. Bandung: ITB

[20] Tanudirjo, Daud. 2011. Indonesia dalam Arus Sejarah. Jakarta: PT. Ichtiar Baru Van Hoeve.

\section{Jurnal:}

[1] Banindro (2010) “Tinjauan Uang Kertas Indonesia"

[2] Banindro (2012) "Kajian Ikonografis Bahasa Rupa Uang Kertas Masa Revolusi”

[3] Herman (2016) "Engraving Mata Uang Kertas Republik Indonesia Masa Pasca Kemerdekaan Tahun 1945-1965"
[4] Subaryono (2013) "Pemanfaatan Media Gambar Pahlawan Nasional Dalam Pembelajaran IPS”

\section{KETERANGAN}

Tulisan ini merupakan bagian dari Tesis saya dengan judul:

"ESTETIKA DAN MAKNA DESAIN MATA UANG KERTAS INDONESIA 1967-1998 SERI PAHLAWAN" 